\title{
A ATUAÇÃO DE ITENS LEXICAIS SUMARIZADORES NA ORGANIZAÇÃO TÓPICA DO DISCURSO
}

\author{
Gustavo Ximenes Cunha, UFMG
}

\section{Introdução}

Estudos sobre referenciação apontam para a grande importância que as nominalizações desempenham na organização das informações que são ativadas num texto. Sua função básica é proceder à categorização de um referente textual, ou seja, é colocar o referente "em determinada categoria cognitivamente estabelecida" (Neves, 2006, p. 100) por meio do emprego de uma expressão nominal anafórica. No entanto, essas expressões nominais podem não categorizar referentes textuais definíveis, mas toda uma passagem anterior do texto. Segundo Koch (2001, p. 82), uma função própria das nominalizações é "sumarizar informações-suporte contidas em segmentos precedentes do texto, encapsulandoas sob a forma de um substantivo-predicativo e transformando-as em objetos-dediscurso". Esse fenômeno, que recebe denominações variadas (encapsulamento, rotulação, sumarização), tem grande importância, porque uma expressão nominal que sumariza uma passagem anterior do texto atua tanto na continuidade quanto na progressão tópica. Se, por um lado, ela reativa informações estocadas na memória do leitor/ouvinte, por outro ela transforma toda aquela passagem em objeto de discurso, o qual poderá constituir o tema ou tópico de enunciados seguintes. Esse tipo de nominalização é importante também, porque a escolha do item lexical utilizado não é aleatória; essa escolha "representa o ponto de vista do falante naquele determinado momento da construção do discurso" (Neves, 2006, p. 102), o que leva a pensar que o emprego de um item lexical pode ser condicionado pela intenção argumentativa do produtor do texto.

Como se vê, o fenômeno que deste ponto em diante denomino sumarização possui grande complexidade. Por essa razão, a sua análise deve levar em conta 
informações de diferentes níveis do discurso, uma vez que fatores de ordem lexical, textual e pragmática participam de sua constituição.

Neste artigo, o objetivo é analisar dois casos de sumarização, constantes de uma matéria jornalística, intitulada "Por que eles querem presidir a Câmara", a qual foi veiculada na revista Veja do dia 12 de janeiro de 2005 . Com a análise dessa matéria, será possível perceber a importância que duas ocorrências de sumarização assumem para a construção de sentidos do texto, bem como para a organização de seus constituintes.

Este artigo está organizado em cinco seções. Na primeira, descreve-se de forma sucinta o instrumento de análise adotado nesse estudo, bem como o percurso de análise seguido. A segunda seção apresenta a análise do papel dos itens lexicais sumarizadores no encadeamento das informações ativadas ao longo da matéria jornalística. Em seguida, na terceira seção, busca-se compreender a função desses itens lexicais na estruturação dos constituintes textuais da matéria da revista $V e j a$. A quarta seção deste artigo apresenta justificativas de ordem referencial para a atuação dos itens lexicais estudados. Por fim, na quinta seção, apresentam-se os resultados obtidos com esse percurso de análise.

\section{Modelo de Análise Modular do Discurso}

Pela complexidade desse tipo de nominalização, do qual, como disse, informações de diferentes níveis do discurso participam, adoto o Modelo de Análise Modular do Discurso como instrumento de análise. Esse modelo concebe o discurso como uma organização muito complexa que pode, por isso mesmo, ser decomposta, num primeiro momento, em domínios específicos de informação, que são os módulos. Com a combinação ou acoplagem de informações dos módulos, chega-se, num segundo momento, à descrição das formas de organização do discurso. As formas de organização chamadas de elementares resultam da acoplagem de informações provenientes apenas dos módulos, enquanto que as

\footnotetext{
${ }^{1} \mathrm{O}$ texto encontra-se segmentado em atos no anexo deste trabalho.
} 
chamadas de complexas resultam da acoplagem de informações dos módulos e de informações de outras formas de organização. Assim, para analisar um texto sob o ponto de vista de sua organização tópica, que é uma forma de organização complexa, busca-se desenvolver o estudo da forma de organização informacional com a acoplagem de informações da forma de organização relacional e dos módulos hierárquico e referencial. A forma de organização tópica resulta da acoplagem de diversos níveis discursivos, porque o seu estudo visa dar conta da maneira como os interlocutores realizam a escolha e o encadeamento das informações ativadas ao longo do texto, o que implica a participação de informações de ordem lingüística, textual e situacional ${ }^{2}$.

Como foi dito, a sumarização é um recurso com o qual o autor/falante categoriza uma porção do texto, transformando-a em objeto de discurso. Ela é, portanto, um recurso que diz respeito ao modo como o produtor do texto faz a escolha e o encadeamento das informações de um texto, ou seja, ela diz respeito à forma de organização tópica.

A seguir, apresento a análise da forma de organização tópica do texto escolhido, focalizando minha atenção nas duas ocorrências de sumarização mencionadas. Os módulos e as formas de organização cujas informações compõem a organização tópica serão brevemente descritos à medida que suas informações forem sendo necessárias.

\section{Forma de organização informacional}

A forma de organização informacional, no Modelo de Análise Modular, tem como objetivo descrever o encadeamento das informações que são ativadas ao longo do discurso, isto é, qual o tipo de encadeamento que liga a informação trazida em cada ato $^{3}$ a elementos da memória discursiva ${ }^{4}$, possibilitando a

\footnotetext{
${ }^{2}$ Para uma melhor compreensão do modelo, ver Roulet, Filliettaz \& Grobet (2001) e Marinho (2004).

${ }^{3}$ Para o Modelo de Análise Modular, o ato é a unidade mínima do discurso (cf. Roulet, Filliettaz \& Grobet, 2001, cap.3).

${ }^{4}$ Para Berrendoner (apud. Roulet, Filliettaz \& Grobet, 2001, p.23), a memória discursiva compreende "os diversos pré-requisitos culturais (normas comunicativas, lugares argumentativos, saberes enciclopédicos
} 
progressão textual e a continuidade referencial. A análise dessa forma de organização pode ser descrita como um processo de ancoragem, uma vez que cada informação ativada pelo ato, a qual se denomina propósito ${ }^{5}$, se ancora em pelo menos uma informação situada na memória discursiva. Para o Modelo de Análise Modular, a informação da memória discursiva mais imediatamente pertinente à qual o ato se encadeia se denomina tópico. O tópico se distingue claramente da marca ou traço lingüístico que o verbaliza, ou seja, das expressões anafóricas que fazem remissão ao tópico.

$\mathrm{E}$ os principais tipos de encadeamento de que trata a organização informacional são progressão linear, progressão com tópico constante e encadeamento à distância. Esses encadeamentos serão especificados a seguir:

(i) Progressão linear: acontece quando o tópico, marcado ou não por um traço anafórico (traço tópico), é proveniente do propósito que precede o ato.

(ii) Progressão com tópico constante: acontece quando o tópico é proveniente do tópico do ato precedente.

(iii) Encadeamento à distância: acontece quando o tópico não tem sua origem no propósito precedente, mas num propósito mais distante.

O quadro abaixo descreve a organização informacional do trecho que vai do ato (17) ao (65) do texto "Por que eles querem presidir a Câmara". A estrutura informacional, tal como representada neste quadro, constitui o resultado da análise da organização informacional de um discurso. Por meio dela, é possível observar o tópico em que cada ato se ancora, a presença ou não de traços que verbalizam o tópico, bem como o tipo de progressão que caracteriza a ancoragem de cada ato ao tópico. Com a estrutura informacional desse trecho, será possível observar que as duas sumarizações mencionadas podem ser estudadas em termos de ancoragem. Esse quadro obedece às seguintes convenções: os atos são transcritos na coluna da esquerda e o tipo de encadeamento que liga o ato ao tópico é apresentado na coluna da direita; o traço tópico é apresentado em negrito e o tópico aparece entre

comuns, etc) que servem de axiomas aos interlocutores para conduzir uma atividade dedutiva", bem como "as enunciações sucessivas que constituem o discurso".

5 A noção de propósito se identifica com a de objeto de discurso, com a diferença de que o propósito é dependente da unidade do ato. 


\section{colchetes, depois do traço; e as informações entre parênteses constituem pontos de}

\section{ancoragem implícitos, ou seja, os tópicos não verbalizados por traço.}

\section{Figura 1: Estrutura informacional do texto "Por que eles querem presidir a}

\section{Câmara"}

\begin{tabular}{|c|c|}
\hline Transcrição da análise da forma de organização informacional & $\begin{array}{l}\text { Progressão } \\
\text { informacional }\end{array}$ \\
\hline \multicolumn{2}{|l|}{$\begin{array}{l}\text { (17) O interesse pessoal dos parlamentares na presidência da Câmara [o grande número de candidatos ao cargo e } \\
\text { a disputa entre V. Guimarães e L. E. Greenhalgh - informação inferível de todo o cotexto anterior] se justifica pela } \\
\text { envergadura política que o cargo confere ao ocupante. }\end{array}$} \\
\hline $\begin{array}{l}\text { (18) (O interesse pessoal dos parlamentares na presidência da Câmara se justifica pela envergadura política que o } \\
\text { cargo confere ao ocupante) Além do eleitorado de Osasco, }\end{array}$ & Progressão linear \\
\hline (19) (Além do eleitorado de Osasco) quem já tinha ouvido falar no deputado João Paulo Cunha? & \multirow{2}{*}{$\begin{array}{l}\text { Progressão linear } \\
\text { Progressão linear }\end{array}$} \\
\hline (20) (Além do eleitorado de Osasco, quem já tinha ouvido falar no deputado João Paulo Cunha?) Hoje, & \\
\hline (21) (Hoje) depois de dois anos na presidência, & Progressão linear \\
\hline (22) ele [João Paulo Cunha]é considerado uma estrela em ascensão. & $\begin{array}{l}\text { Encadeamento à } \\
\text { distância }\end{array}$ \\
\hline (23) (João Paulo Cunha) É cotado para integrar a equipe ministerial do governo Lula & Tópico constante \\
\hline (24) (João Paulo Cunha) e também consta da relação dos aspirantes a candic & Tópico constante \\
\hline $\begin{array}{l}\text { (25) (ele é considerado uma estrela em ascensão. É cotado para integrar a equipe ministerial do governo Lula e } \\
\text { também consta da relação dos aspirantes a candidato ao governo de São Paulo) "É mais importante ser presidente da } \\
\text { Câmara do que ocupar um ministério. }\end{array}$ & Progressão linear \\
\hline $\begin{array}{l}\text { (26) ("É mais importante ser presidente da Câmara do que ocupar um ministério) Ministros recebem ordens do } \\
\text { presidente da república. }\end{array}$ & Progressão linear \\
\hline $\begin{array}{l}\text { (27) ("É mais importante ser presidente da Câmara do que ocupar um ministério) Presidentes da Câmara recebem } \\
\text { pedidos", }\end{array}$ & Tópico constante \\
\hline $\begin{array}{l}\text { (28) ("É mais importante ser presidente da Câmara do que ocupar um ministério. Ministros recebem ordens do } \\
\text { presidente da república. Presidentes da Câmara recebem pedidos") diz o deputado Michel Temer (PMDB-SP), }\end{array}$ & Progressão linear \\
\hline (29) que[Michel Temer] ocupou o cargo entre 1997 e 2001. & Progressão linear \\
\hline (30) O presidente da Câmara [presidente da Câmara] pode não ajudar, & $\begin{array}{ll}\begin{array}{l}\text { Encadeamento } \\
\text { distância }\end{array} & \text { à } \\
\end{array}$ \\
\hline 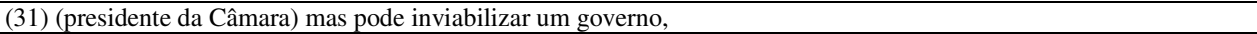 & Tópico constante \\
\hline s são suas [do p & nstante \\
\hline (33) É dele [do presidente da Câmara] a decisão do que vai ou não entrar na pauta de votação. & Tópico constante \\
\hline (34) Assim, dependendo de seu [do presidente da Câmara] humor, & Tópico constante \\
\hline (35) (o pr & Tópico constante \\
\hline (36) ( & linear \\
\hline (37) (No a & Progressão linear \\
\hline (38) (apenas seis propostas de autoria de & Progressão linear \\
\hline (39) Por isso o governo aposta tanto na eleição de Greenhalgh [Greenhalgh], homem de confiança da cúpu & $\begin{array}{l}\text { Encadeamento } \\
\text { distância }\end{array}$ \\
\hline $\begin{array}{l}\text { (40) (presidente da Câmara) Outra exclusividade do presidente é a definição do ritmo das apurações de irregularidades } \\
\text { na Casa. }\end{array}$ & $\begin{array}{l}\text { Encadeamento } \\
\text { distância }\end{array}$ \\
\hline $\begin{array}{l}\text { (41) (o ritmo das apurações de irregularidades na Casa) O processo de cassação do deputado André Luiz (PMDB-RJ), } \\
\text { por exemplo, andou rápido por empenho de João Paulo. }\end{array}$ & Progressão linear \\
\hline $\begin{array}{l}\text { (42) (o ritmo das apurações de irregularidades na Casa) Outro, como o do deputado Pedro Corrêa, envolvido com a } \\
\text { máfia dos combustíveis, está se arrastando há seis meses. }\end{array}$ & Tópico constante \\
\hline (43) Com tantos poderes [informação cotextual - atos 25-42], & Progressão linear \\
\hline (44) (Com tantos poderes) o governo bajula e os deputados prestam reverência a seu presidente. & Progressão linear \\
\hline (45) Tudo isso [o governo bajula e os deputados prestam reverência a seu presidente] é sinônimo de poder. & Progressão linear \\
\hline (46) A Câmara[Casa] tem números gigantescos & $\begin{array}{l}\text { Encadeamento } \\
\text { distância }\end{array}$ \\
\hline (47) (A Câmara) e oferece uma vida bem melhor a seu presidente do que aos outros $512 \mathrm{c}$ & Tópico constante \\
\hline (48) (A Câmara tem números gigantescos) $\mathrm{O}$ orçamento anual é de 2,3 bilhões de reais, & $\begin{array}{l}\text { Encadeamento } \\
\text { distância }\end{array}$ \\
\hline (49) valor $[2,3$ bilhõe & Progressão linear \\
\hline (50) (todos os municípios brasileiros) com & Progressão linear \\
\hline $\begin{array}{l}\text { (51) (A Câmara oferece uma vida bem melhor a seu presidente do que aos outros } 512 \text { ocupantes da Casa) A residência } \\
\text { oficial do presidente fica num terreno de } 9.000 \text { metros quadrados, à beira do lago Paranoá. }\end{array}$ & $\begin{array}{l}\text { Encadeamento } \\
\text { distância }\end{array}$ \\
\hline (52) O imóvel [a residência oficial do presidente] tem suíte, três quartos, escritório, salão de festas e piscina. & Progressão linear \\
\hline $\begin{array}{l}\text { (53) O presidente [o presidente] dispõe de um staff de } 21 \text { funcionários, entre faxineiros, cozinheiros, jardineiros, } \\
\text { motoristas e seguranças, }\end{array}$ & $\begin{array}{l}\text { Encadeamento } \\
\text { distância }\end{array}$ \\
\hline (54) para cuidar de tudo[O imóvel tem suíte, três quartos, escritório, salão de festas e piscina]. & $\begin{array}{l}\text { Encadeamento } \\
\text { distância }\end{array}$ \\
\hline $\begin{array}{l}\text { (55) A equipe [um staff de } 21 \text { funcionários] é comandada } \\
\text { pública. }\end{array}$ & $\begin{array}{l}\text { Encadeamento } \\
\text { distância }\end{array}$ \\
\hline
\end{tabular}




\begin{tabular}{|c|c|}
\hline (56) "A estrutura da casa [a residência oficial do presidente] é tão boa que você liga duas horas antes & $\begin{array}{l}\text { Encadeamento à } \\
\text { distância }\end{array}$ \\
\hline (57) (você) e avisa que vai levar trinta pessoas para o jantar. & Progressão linear \\
\hline (58) (você) Pode chegar tranqüilamente que o jantar vai estar na mesa", & Tópico constante \\
\hline $\begin{array}{l}\text { (59) ("A estrutura da casa é tão boa que você liga duas horas antes e avisa que vai levar trinta pessoas para o jantar. } \\
\text { Pode chegar tranqüilamente que o jantar vai estar na mesa") testemunha Michel Temer. }\end{array}$ & Progressão linear \\
\hline (60) A residência oficial [a residência oficial do presidente] é ponto de referência para encontros importantes. & \begin{tabular}{|l} 
Encadeamento à \\
distância
\end{tabular} \\
\hline (61) (A residência oficial é ponto de referência para encontros importantes) Nos últimos c & Progressão linear \\
\hline (62) (Nos últimos dois anos) João Paulo Cunha recebeu quatro vezes o presidente Lula. & Progressão linear \\
\hline $\begin{array}{l}\text { (63) (A residência oficial é ponto de referência para encontros importantes) Os principais pontos das reformas } \\
\text { tributária e previdenciária foram definidos em reuniões realizadas na residência oficial. }\end{array}$ & $\begin{array}{ll}\text { Encadeamento à } \\
\text { distância }\end{array}$ \\
\hline (64) Com tantos atrativos [informação cotextual - atos 17-63], & Progressão linear \\
\hline (65) (Com tantos atrativos) é natural que não faltem interessados em ocupar a cc & Progressão linear \\
\hline
\end{tabular}

Não descrevo esse quadro em detalhe, porque ele apresenta a estrutura informacional de maneira clara e os objetivos aqui são localizar as ocorrências de sumarização, observar qual a porção do texto que o item lexical sumariza e qual o tipo de encadeamento que liga o ato em que o item aparece às informações mais pertinentes para esse ato, o tópico.

O primeiro caso de sumarização ocorre no ato 43 (Com tantos poderes), e o segundo ocorre no ato 64 (Com tantos atrativos). Interpreto que os itens lexicais "poderes" e "atrativos" são traços tópicos que sumarizam os seus tópicos, ou seja, as porções do texto que vão do ato 25 ao 42 e do ato 17 ao 63, respectivamente. O que a estrutura informacional mostra é que, com a sumarização, informações que não estavam mais totalmente ativadas na consciência do leitor são reativadas e transformadas em um novo referente, com o qual o discurso prossegue. Isso mostra que a sumarização tem, de fato, importância tanto para a continuidade (reativação de informações) como para a progressão (introdução/ativação de novos referentes).

Quanto ao tipo de encadeamento, interpreto que os atos 43 e 64 se ancoram aos seus tópicos por progressão linear. Como foi dito, a progressão linear acontece quando o tópico de um ato é proveniente do propósito que precede esse ato. Nos casos de sumarização analisados, o tópico dos atos 43 e 64 não se restringe ao propósito dos atos 42 e 63; ele engloba os propósitos de vários atos precedentes. Mas, como esses vários atos precedem imediatamente os atos 43 e 64, interpreto que os atos em que ocorrem as sumarizações se encadeiam aos tópicos por progressão linear. 


\section{Módulo hierárquico e forma de organização relacional ${ }^{6}$}

O módulo hierárquico é o responsável por definir os constituintes de base da estrutura do texto e por definir as regras que permitem gerar as estruturas hierárquicas de todos os textos possíveis. Essas estruturas hierárquicas são hipóteses interpretativas da forma de negociação subjacente a um dado texto. Por meio dessas estruturas, é possível a visualização das hierarquias e das relações que os constituintes do texto (trocas, intervenções e atos) estabelecem entre si.

A forma de organização relacional resulta da acoplagem de informações hierárquicas e lexicais, quando a relação entre os constituintes textuais é marcada por um conector, ou da acoplagem de informações hierárquicas e referenciais, quando a relação não é marcada (Roulet, 1999). O estudo dessa forma de organização se ocupa do estudo das relações que se estabelecem entre um constituinte do texto e informações disponíveis na memória discursiva, que podem ou não ter sua origem no constituinte anterior. Esse estudo ocorre em duas etapas. $\mathrm{Na}$ primeira, descrevem-se as relações textuais genéricas entre os constituintes da estrutura hierárquica e informações estocadas na memória discursiva, com base numa lista reduzida de categorias ${ }^{7}$ e com base nas propriedades dos conectores que marcam as relações ou que poderiam marcá-las. Na segunda etapa, descrevem-se os percursos inferenciais que permitem determinar a relação específica entre os constituintes textuais e as informações da memória discursiva, com a aplicação de um princípio geral de cálculo inferencial, com base nas propriedades lingüísticas e contextuais dos constituintes. (Roulet, Fillietaz \& Grobet, 2001, cap. 6.). Em vista dos objetivos deste artigo, não será necessário chegar à segunda etapa de análise da organização relacional.

Apresento, a seguir, a macro-estrutura hierárquico-relacional do texto "Por que eles querem presidir a Câmara".

\footnotetext{
${ }^{6}$ Opto por apresentar o módulo hierárquico e a forma de organização relacional na mesma seção, porque a estrutura que apresento mais adiante resulta da acoplagem desse módulo e dessa forma de organização do discurso.

${ }^{7}$ Segundo o Modelo de Análise Modular, essas categorias são: argumento, contra-argumento, reformulação, comentário, topicalização, sucessão, preparação e clarificação.
} 
Figura 2: Macro-estrutura hierárquico-relacional do texto "Por que eles querem presidir a Câmara”.

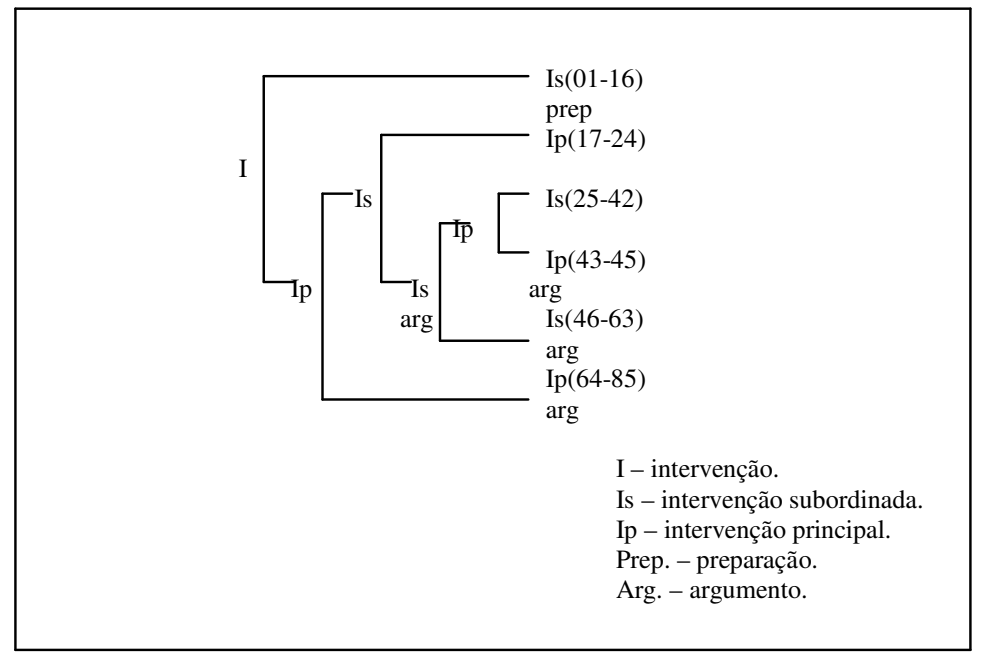

Com essa macro-estrutura, é possível ver que as intervenções que os atos 43 e 64 introduzem se ligam às intervenções anteriores por uma relação de argumento e têm o estatuto de principais. As intervenções introduzidas pelos atos 43 e 64 são principais, porque trazem conclusões para o que se disse na Is(25-42) e na Is(1763), respectivamente. É interessante notar que o item lexical "poderes", no ato 44, sumariza todas as informações contidas na Is(25-42), transformando-as no referente com o qual se inicia uma conclusão para as informações sumarizadas. $\mathrm{O}$ mesmo acontece com o item lexical "atrativos", no ato 64. Ele sumariza as informações da Is(17-63), transformando-as no referente com que se inicia a grande intervenção conclusiva do texto, Ip(64-85), a qual coincide com o último parágrafo.

Com base nessas observações, acredito que os atos 43 e 64 desempenham um importante papel na estruturação do texto. Da mesma forma que o fariam conectores como "portanto" e "conseqüentemente", eles sinalizam para o leitor que as intervenções que trazem são constituintes principais e conclusivos:

Portanto/conseqüentemente, (44) o governo bajula e os deputados prestam reverência a seu presidente (...). 
Portanto/conseqüentemente, (65) é natural que não faltem interessados em ocupar a cadeira de presidente (...).

Entretanto, a opção pelo emprego de atos que sumarizam informações com os itens lexicais "poderes" e "atrativos" no lugar de conectores não é gratuita, como será mostrado na próxima seção.

Acoplando informações da estrutura informacional com informações da estrutura hierárquico-relacional, observa-se que esse tipo de nominalização que sumariza porções do texto pode ter uma atuação importante tanto na construção da cadeia referencial (reativando informações e transformando-as em referentes) quanto na estruturação do texto (sinalizando a natureza dos constituintes que introduz). Observa-se ainda que as informações (os propósitos) ativadas pelas intervenções que se iniciam com os atos 43 e 64 são informações que têm o estatuto de principais, o que pode trazer implicações para a construção de sentidos do texto. Isso porque as informações de que os políticos que disputam o cargo de presidente da Câmara se deixam seduzir por poder e de que luxo e dinheiro são para eles atrativos poderão ficar mais acessíveis na memória discursiva do leitor.

\section{Módulo referencial}

O módulo referencial é aquele que estuda as relações entre as produções verbais e o mundo em que são enunciadas, bem como entre as produções verbais e o mundo que representam, na tentativa de explicitar os acontecimentos e os objetos, tal como eles são percebidos e construídos pelos interlocutores. Ao tratar desse módulo, Fillietaz (Roulet, Fillietaz \& Grobet, 2001, p.132) diz que, "nas situações de interação efetivas, caracterizadas por enjeux específicos, os agentes mobilizam recursos conceituais tipificados, mas que os atualizam em configurações particulares". Essas configurações particulares constituem as estruturas emergentes ou conceituais, as quais são descritas como sendo "o produto de uma negociação na qual os agentes se adaptam permanentemente às especificidades da situação" (Roulet, Fillietaz \& Grobet, 2001, p. 135). Dito de outro modo, essas estruturas são 
responsáveis pela descrição dos conceitos que são ativados ao longo do discurso e pela descrição das relações de derivação ou outras que há entre esses conceitos.

A seguir, apresento a estrutura conceitual do trecho que compreende a Ip(25-45), para estudar o que autoriza a sumarização das informações da Is(25-42) pelo item "poderes".

Figura 3: Estrutura conceitual da Ip(25-45)

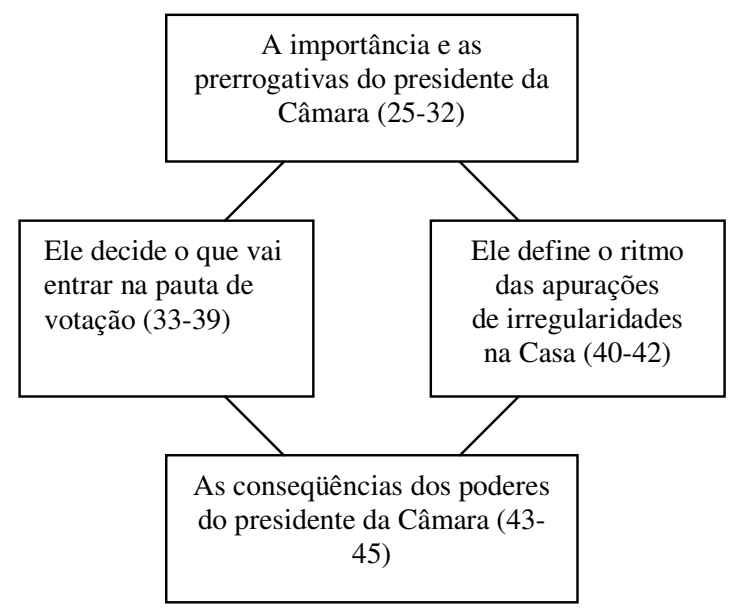

O autor inicia esse trecho com uma declaração do deputado Michel Temer, em que este evidencia a importância do presidente da Câmara em relação aos ministros. Essa declaração abre espaço para o autor dizer que são muitas as prerrogativas do presidente. Em seguida, há a explicitação de quais são essas prerrogativas: é ele quem decide o que vai entrar na pauta de votação, bem como quem define o ritmo das apurações de irregularidades na Casa. Por fim, o autor diz que esses poderes (o fato de ser mais importante que ministros e de ter tantas prerrogativas) têm como conseqüências a bajulação do governo e a reverência dos deputados ao presidente da Câmara.

A sumarização de informações pelo item lexical "poderes" parece se justificar pelo fato de que toda essa Ip(25-45) tem como tópico a importância e as prerrogativas do presidente da Câmara. Sendo esse o assunto de que trata toda a intervenção, parece natural que ele seja retomado pelo item "poderes", porque faz 
parte da memória discursiva dos interlocutores a informação de que ser importante para o governo e ter prerrogativas junto a ele significa poder.

A seguir, apresento a estrutura conceitual do trecho que compreende a Ip(17-85), para verificar o que autoriza a sumarização de informações pelo item "atrativos".

Figura 4: Estrutura conceitual da Ip(17-85)

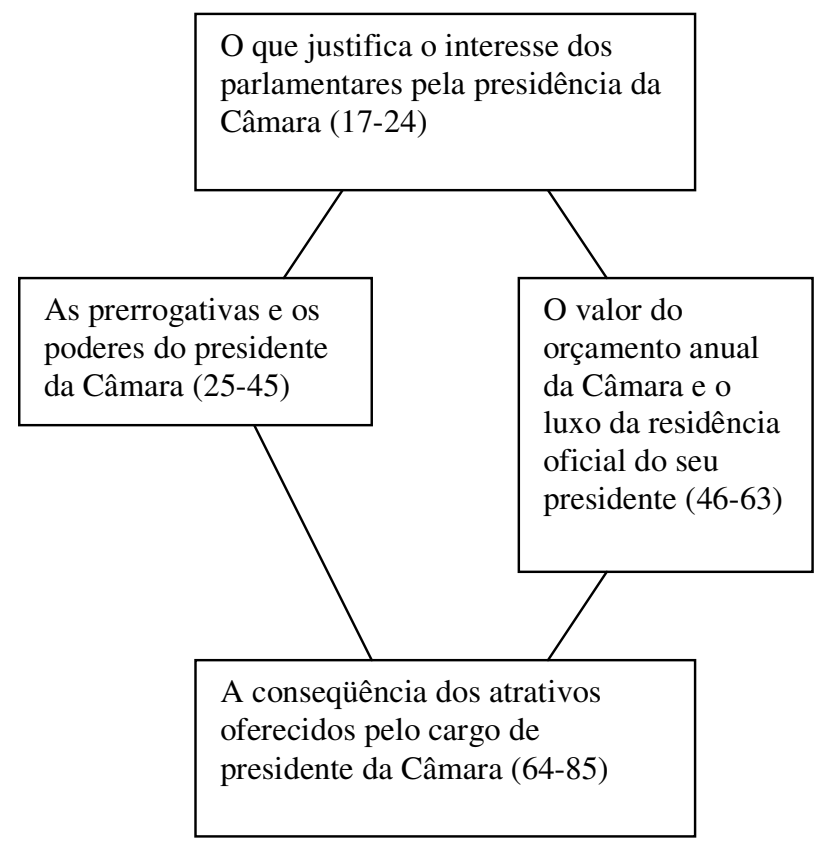

$\mathrm{O}$ autor inicia esse trecho dizendo que a justificativa para o interesse dos deputados na presidência da Câmara é a envergadura política que o cargo confere ao ocupante. Em seguida, ele explicita qual é a envergadura política do presidente da Câmara: o presidente assume poderes e ganha prerrogativas não compartilhados por nenhum outro político; além disso, o orçamento anual da Câmara é de 2,3 bilhões de reais, e a residência oficial do presidente é luxuosa e possui uma equipe de funcionários especializados, preparada para organizar jantares e encontros políticos. Por último, o autor diz que é natural que, com tantos atrativos, não faltem deputados interessados em assumir o cargo de presidente da Câmara.

A sumarização de informações pelo item "atrativos" parece se justificar por duas informações do conhecimento de mundo dos interlocutores. A primeira é a de 
que poder, luxo e dinheiro constituem elementos pelos quais muitas pessoas se sentem atraídas. A segunda informação diz respeito à representação estereotípica do político brasileiro, o qual, segundo essa representação, se interessa mais em alcançar benefícios para si (poder, luxo e dinheiro) do que para os que o elegeram. Com base nessas informações, torna-se justificável sumarizar as características próprias do cargo de presidente da Câmara pelo item “atrativos”, a fim de trazer a conseqüência que esses atrativos implicam: o grande número de políticos interessados em assumir o cargo.

Acoplando informações da estrutura informacional com informações da estrutura conceitual, obtém-se o percurso conceitual que subjaz à aparente linearidade da estrutura informacional. Assim, é possível observar que o autor, em cada um dos trechos descritos nas estruturas conceituais, traz um tópico (ou hipertópico), do qual derivam dois conceitos. Desses conceitos, que ocupam uma posição intermediária na estrutura, deriva, por sua vez, o conceito que desempenha o papel de conclusão para o que se disse, em cujo início há a presença de um item lexical que sumariza as informações precedentes (o hiper-tópico e os conceitos intermediários).

Acoplando informações da estrutura informacional com informações da estrutura conceitual e hierárquico-relacional, obtém-se a explicação para a preferência do autor em empregar um ato com um item lexical que sumariza informações a empregar um conector conclusivo. Como foi dito na seção anterior, os atos 43 e 64 têm um papel importante na articulação do texto, porque eles sinalizam para o leitor que as intervenções que encabeçam trazem uma conclusão para as intervenções que os precedem. Foi dito também que os atos 43 e 64 têm a mesma atuação de conectores conclusivos e que esses atos poderiam ser substituídos por conectores como "portanto" ou "conseqüentemente". Entretanto, o uso de um item lexical que sumariza uma porção do texto não é aleatório.

Um motivo para o uso desse tipo de nominalização pode ser que a reativação de informações da memória discursiva sob os nomes "poderes" e "atrativos" 
implica assumir perante o leitor uma intenção argumentativa, uma vez que, para o autor, os políticos que disputam a presidência da Câmara se deixam seduzir pelos poderes inerentes ao cargo, bem como se sentem atraídos por luxo e dinheiro. Mas, como ele busca também a adesão do leitor, o autor joga com os conhecimentos de mundo partilhados, segundo os quais ter importância no governo é sinônimo de poder e segundo os quais luxo e dinheiro atraem políticos. Embora os conectores explicitem para o leitor um percurso de leitura que, muitas vezes, tem sua origem na intenção argumentativa do produtor do texto, nos casos em análise a sua atuação não seria tão eficaz quanto a das sumarizações. Isso porque a natureza mais procedural do que conceitual dos conectores impede que eles categorizem porções do texto, transformando-as em objetos de discurso ou representações mentais, como o fazem as sumarizações. Portanto, o uso do conector no lugar dos atos $43 \mathrm{e}$ 64 poderia implicar uma atenuação da força argumentativa que se obtém com o tipo de nominalização, utilizado no texto.

\section{Considerações finais}

Com este artigo, busquei mostrar que o tipo de nominalização que sumariza segmentos precedentes do texto é um fenômeno complexo e que diz respeito à forma de organização tópica do discurso. A complexidade própria da sumarização exige que, em sua análise, sejam levadas em consideração informações de diferentes níveis discursivos. Por essa razão, optou-se pelo uso do Modelo de Análise Modular do Discurso como instrumento de análise. Esse modelo propõe a distinção das várias informações de ordem lingüística, textual e situacional que entram em jogo na constituição do discurso. Utilizando esse instrumento, pude

mostrar que as sumarizações presentes na matéria jornalística "Por que eles querem presidir a Câmara" desempenham função importante tanto na construção da cadeia referencial (reativando informações e transformando-as em referentes) quanto na estruturação do texto (sinalizando a natureza dos constituintes que introduzem). Além disso, pude mostrar que o que autoriza o emprego das sumarizações é a 
estrutura conceitual subjacente ao texto e que o que explica a sumarização de segmentos do texto com os itens lexicais "poderes" e "atrativos" é a intenção argumentativa do autor.

\section{Referências bibliográficas}

KOCH, I. G. V. A referenciação como atividade cognitiva e interacional. Boletim da ABRALIN 26 - número especial, 2001.

MARINHO, J. H. C. Uma abordagem modular e interacionista da organização do discurso. In: Revista da Anpoll 16. São Paulo. Jan/jun. 2004, p. 75-100.

NEVES, M. H. M. Gramática e texto. São Paulo: Contexto, 2006.

ROULET, E. Description de l'organisation du discourse. Du dialogue au texte. Paris: Didier, 1999.

ROULET, E.; FILLIETTAZ, L.; GROBET, A. Un modèle et un instrument d'analyse de l'organisation du discours. Berne: Lang, 2001. 


\section{ANEXO \\ Por que eles querem presidir a Câmara}

(01) Os deputados Luiz Eduardo Greenhalgh e Virgílio Guimarães, ambos do PT, passaram a semana trabalhando pesado (02) _ uma cena rara em Brasília, (03) em especial neste período do ano. (04) Os dois estão em campanha pela presidência da Câmara dos Deputados. (05) Pela tradição, (06) o cargo é ocupado por um parlamentar indicado pelo partido que detém a maior bancada. (07) Ao PT, portanto, (08) que tem o maior número de deputados, (09) bastaria apontar um nome. (10) Mas, como nada no mundo petista pode ser assim tão simples, apareceram logo onze candidatos. (11) Depois de dois meses de muitas reuniões, (12) chegouse a um nome de consenso: o de Greenhalgh, (13) mas Virgílio Guimarães decidiu continuar no páreo por conta própria. (14) Até fevereiro, (15) quando ocorrerá a eleição, (16) outros candidatos devem aparecer. (17) $\mathrm{O}$ interesse pessoal dos parlamentares na presidência da Câmara se justifica pela envergadura política que o cargo confere ao ocupante. (18) Além do eleitorado de Osasco, (19) quem já tinha ouvido falar no deputado João Paulo Cunha? (20) Hoje, (21) depois de dois anos na presidência, (22) ele é considerado uma estrela em ascensão. (23) É cotado para integrar a equipe ministerial do governo Lula (24) e também consta da relação dos aspirantes a candidato ao governo de São Paulo.

(25) "É mais importante ser presidente da Câmara do que ocupar um ministério. (26) Ministros recebem ordens do presidente da república. (27) Presidentes da Câmara recebem pedidos", (28) diz o deputado Michel Temer (PMDB-SP), (29) que ocupou o cargo entre 1997 e 2001. (30) O presidente da Câmara pode não ajudar, (31) mas pode inviabilizar um governo, (32) tantas são suas prerrogativas. (33) É dele a decisão do que vai ou não entrar na pauta de votação. (34) Assim, dependendo de seu humor, (35) pode acelerar ou retardar matérias de interesse do executivo. (36) No ano passado, (37) apenas seis propostas de autoria de deputados foram aprovadas, (38) contra mais de 100 do Executivo. (39) Por isso o governo aposta tanto na eleição de Greenhalgh, homem de confiança da cúpula petista. (40) Outra exclusividade do presidente é a definição do ritmo das apurações de irregularidades na Casa. (41) O processo de cassação do deputado André Luiz (PMDB-RJ), por exemplo, andou rápido por empenho de João Paulo. (42) Outro, como o do deputado Pedro Corrêa, envolvido com a máfia dos combustíveis, está se arrastando há seis meses. (43) Com tantos poderes, (44) o 
governo bajula e os deputados prestam reverência a seu presidente. (45) Tudo isso é sinônimo de poder.

(46) A Câmara tem números gigantescos (47) e oferece uma vida bem melhor a seu presidente do que aos outros 512 ocupantes da Casa. (48) O orçamento anual é de 2,3 bilhões de reais, (49) valor superior à arrecadação de todos os municípios brasileiros, (50) com exceção de São Paulo e do Rio de Janeiro. (51) A residência oficial do presidente fica num terreno de 9.000 metros quadrados, à beira do lago Paranoá. (52) O imóvel tem suíte, três quartos, escritório, salão de festas e piscina. (53) O presidente dispõe de um staff de 21 funcionários, entre faxineiros, cozinheiros, jardineiros, motoristas e seguranças, (54) para cuidar de tudo. (55) A equipe é comandada por uma nutricionista, com mestrado em administração pública. (56) "A estrutura da casa é tão boa que você liga duas horas antes (57) e avisa que vai levar trinta pessoas para o jantar. (58) Pode chegar tranqüilamente que o jantar vai estar na mesa", (59) testemunha Michel Temer. (60) A residência oficial é ponto de referência para encontros importantes. (61) Nos últimos dois anos, (62) João Paulo Cunha recebeu quatro vezes o presidente Lula. (63) Os principais pontos das reformas tributária e previdenciária foram definidos em reuniões realizadas na residência oficial.

(64) Com tantos atrativos, (65) é natural que não faltem interessados em ocupar a cadeira de presidente. (66) Em dezembro, (67) Greenhalgh foi o escolhido, com a benção do Planalto e da cúpula petista. (68) Até então favorito para o cargo, (69) o mineiro Virgílio, que foi relator da reforma tributária e já dividiu um apartamento com o então deputado Lula durante a Constituinte, se rebelou (70) e afirma que levará sua candidatura até o fim. (71) Ele não se conforma por ter sido vetado pelo Planalto e por Lula. (72) Já Greenhalgh, que tem tudo para vencer a disputa, é apoiado pelas principais lideranças, (73) mas odiado pelas bases. (74) Ele enfrenta a resistência dos mais conservadores, (75) devido a sua atuação como advogado de vítimas do regime militar e dos sem-terra. (76) A maioria das críticas gira em torno de seu comportamento, (77) definido como arrogante por alguns. (78) "Há muitos deputados que realmente não conheço, (79) mas eu não era candidato (80) e não tinha obrigação de conhecêlos”, (81) responde Greenhalgh. (82) O vencedor da disputa conquistará poder, influência e visibilidade. (83) Ainda assim, o cargo reserva alguns estigmas a seus ocupantes. (84) À exceção de Aécio Neves, que antecedeu João Paulo Cunha e se elegeu governador de Minas, (85) nos últimos vinte anos nenhum dos ex-presidentes da Câmara alçou vôos maiores. 
Revista Veja (12/01/2005) 